\title{
EQUIDADE PREVIDENCIÁRIA NA ÁREA RURAL DO BRASIL: 1988 A $20088^{1,2}$
}

\author{
Flávio Braga de Almeida-Gabriel ${ }^{3}$ \\ Carlos Roberto Ferreira ${ }^{4}$ \\ Solange de Cássia Inforzato de Souza
}

Resumo: O objetivo deste artigo é analisar a evolução da concentração de renda na área rural brasileiro após a promulgação da Legislação de 1988 e as leis que se seguiram no âmbito da seguridade do trabalhador rural (Lei 8.212/91 e Lei 8213/91). Os procedimentos metodológicos envolvem a revisão da legislação, a verificação da participação e da medida de concentração das aposentadorias e pensões na distribuição de renda rural pós Lei 8213/91 e exposição do debate na literatura. Utiliza-se a decomposição do Índice de Gini para avaliar a distribuição de renda a partir dos microdados da PNAD de 1988 a 2008. Os resultados da pesquisa permitem afirmar que houve redução na concentração de renda, de 0,559 em 1988 para 0,498 em 2008, explicada, em parte, pelas mudanças no mercado de trabalho rural (trabalho principal) e pelo aumento do valor do salário mínimo real entre 1994 e 2004. Entretanto, a renda derivada das aposentadorias e pensões rurais mostrou-se concentrada, cujo índice de Gini foi de 0,417 em 1988 para 0,569 em 2008.

Palavras-chave: Previdência rural, Distribuição de renda, Índice de Gini.

Abstract: The aim of this paper is to analyze the evolution of income concentration in the Brazilian rural area after the promulgation of the 1988 legislation and laws that followed under the security of the rural worker (Law 8212/91 and Law 8213/91). The methodological procedures involved the review of legislation, the verification of participation and the extent of concentration of pensions in rural income distribution after exposure of Law 8213/91 and debate in the literature. It uses the decomposition of the Gini index to measure income distribution, based on microdata from PNAD 1988 to 2008. The survey results have revealed that there was a reduction in the income concentration, from 0.559 in 1988 to 0.498 in 2008 , partly explained by changes in the

\footnotetext{
Os autores agradecem ao CNPQ pelo financiamento da pesquisa.

2 Recebido em: 15/12/2010. Aceito em: 15/02/2011.

3 Economista, mestrando em Economia Regional pela Universidade Estadual de Londrina, bolsista Capes. E-mail: fbagabriel@ig.com.br.

4 Economista, Doutor em Economia Aplicada pela Escola Superior de Agricultura Luiz de Queiroz (ESALQ/ USP). Professor Adjunto do Departamento de Economia da Universidade Estadual de Londrina. Email: robert@uel.br.

5 Economista, Doutora em Educação: história, política, sociedade, pela Pontifícia Universidade Católica de São Paulo. Professora Associada do Departamento de Economia da Universidade Estadual de Londrina. E-mail: solangecassia@uol.com.br.
} 
rural labor market (main job) and the rising value of the real minimum wage between 1994 and 2004. However, income derived from pensions rural proved concentrated, which Gini index was 0.417 in 1988 and 0.569 in 2008.

Key-words: rural social welfare, income distribution, Gini index.

\section{Introdução}

A concessão dos benefícios das aposentadorias e pensões faz do sistema previdenciário importante ator na economia como um todo, por injetar recursos financeiros e movimentá-la, além de ser responsável pelo bemestar das pessoas e famílias atingidas por tais benefícios, proporcionando, ao indivíduo segurado, os recursos em momentos adversos de sua vida.

A Constituição de 1988 foi um marco para os trabalhadores rurais, cujo texto os beneficiou de forma a igualá-los a todos os trabalhadores brasileiros, com a introdução do princípio do acesso universal de idosos e inválidos de ambos os sexos à Previdência Social. Sua regulamentação, pelas Leis 8.212 (Plano de Custeio) e 8.213 (Plano de Benefícios) em 1991, trouxe alteração conceitual profunda para o programa previdenciário rural no Brasil, no qual a Previdência Social aparentou buscar a equidade na distribuição de seus benefícios.

Como mencionado por Stephanes (1998, p.18), "a equidade num sistema previdenciário tem de ser ponto de partida das discussões envolvendo o tema. Assim, será possível dar um rumo correto para as políticas públicas". James \& Brooks (2001) acreditam que a equidade na distribuição de benefícios incentiva sua existência por motivar seus contribuintes a participar do sistema. Thompson (2000) considera que todo e qualquer sistema de previdência social pode servir como redistribuidor de renda através de seus benefícios.

De acordo com Campolina et al. (2009), as diferenças relacionadas à renda e condições de moradia das áreas urbanas e rurais diminuíram nas 
duas últimas décadas, o que não significa equiparação entre urbano e rural, causadas por transformações no mercado de trabalho rural, pelo acesso de proventos oriundos do sistema previdenciário e de transferências governamentais. As áreas rurais diferem, em parte, das áreas urbanas, dadas as suas singularidades, como o fato da maior numerosidade familiar e menor taxas de alfabetizados, e também pela dependência das transferências governamentais, além de serem direcionadas, na maior parte, para gastos com alimentação e menos com gastos com educação, saúde e habitação.

Alguns pesquisadores tratam dessas transformações no meio rural, sobretudo após a década de 1990, utilizando a Pesquisa Nacional por Amostra de Domicílio (PNAD), e observam a forma com que as mudanças na agricultura e no mercado de trabalho agrícola afetam a ruralidade nacional. Destacam-se os trabalhos de Campolina et al. (2009), Ferreira et al. (2006), Del Grossi e Graziano da Silva (2006), Kageyama (2003 e 2004), Graziano da Silva e Del Grossi (2001), Campanhola e Graziano da Silva (2000), Graziano da Silva (1996). Esses trabalhos apontaram alguns fenômenos importantes oriundos de mudanças na ocupação do trabalho rural, destacados no trabalho de Ferreira et al. (2006): mecanização da produção e a introdução de tecnologias poupadoras de mão de obra, expansão de área produtiva, surgimento de novas culturas e variedades com distintos requisitos de manejo, além da abertura comercial e financeira da economia brasileira que impulsionou a transação de commodities agrícolas.

A fonte de renda das famílias das áreas rurais também passou por alterações, como aponta Ferreira et al. (2009), principalmente, a partir do início da década de 1990. As rendas das aposentadorias e pensões passaram a ter maior representatividade em detrimento do trabalho principal, pois enquanto o primeiro fator aumentou $81,3 \%$ entre $1990 \mathrm{e}$ 2006 , o segundo diminuiu $10,9 \%$. Os autores atribuem a significativa mudança, em parte, à elevação no número de benefícios rurais em $70 \%$ entre 1988 e 1992, período de regulamentação do processo constitucional. 
Para o Brasil, como um todo, trabalhos mais recentes divergem sobre sua contribuição para a desigualdade da distribuição da renda. Hoffmann (2003 e 2009), Hoffmann e Leone (2004), Ferreira (2003 e 2006), Ferreira et al. (2009) e Nicholson (2007) apontam a concentração de renda provocada pelas aposentadorias e pensões. No entanto, Dedecca et al. (2006 e 2007) e IPEA (2008) evidenciam o contrário. Da avaliação das aposentadorias e pensões rurais, poucos são os trabalhos que abordem o assunto, com exceção de Ferreira e Souza (2007) e Ferreira et al. (2009).

Diante deste contexto, a problemática desta pesquisa envolve a participação das aposentadorias e pensões na formação da renda domiciliar per capita e o seu papel na distribuição da renda na área rural brasileira a partir da década de 80 . Assim, o presente estudo busca medir e analisar a influência das rendas das aposentadorias e pensões na área rural para a concentração do rendimento domiciliar per capita após 1988, utilizando a decomposição do índice de Gini.

Este trabalho está organizado em cinco partes, começando por esta introdução. A segunda parte trata de um breve histórico da previdência rural brasileira. A terceira dispõe sobre a base de dados e a metodologia utilizada para realização deste trabalho. Na seção seguinte, são analisados os resultados da decomposição do Índice de Gini, especificamente, no Brasil Rural para, ao final, apresentar as considerações finais.

\section{Previdência Rural Brasileira: Um Breve Histórico}

Até a década de 1960, os trabalhadores rurais, maioria da população brasileira, não tinham acesso à seguridade social. Embora a Constituição de 1934, em seu texto, dissesse que todo trabalhador brasileiro teria direito à seguridade, esse benefício não era estendido ao trabalhador rural (MALLOY, 1976).

A transformação mais significativa ocorreu em 1971 com a criação do programa Prorural (sob a responsabilidade do Funrural) pela Lei 
Complementar $n^{\circ} 11$, que oferecia como benefícios a aposentadoria por idade aos 65 anos (no valor de 1/2 salário mínimo), aposentadoria por invalidez (no valor de $1 / 2$ salário mínimo), pensão para viúvas e órfãos (no valor de 30\% do salário mínimo), auxílio-funeral e assistência médica.

Em 1977, foi criado o Sistema Nacional de Previdência e Assistência Social (Sinpas). O programa de benefícios monetários passou a ser administrado pelo INPS, os benefícios médicos passaram a ser administrados pelo Instituto Nacional de Assistência Médica da Previdência Social (Inamps) e a instituição administrativa Funrural foi extinta (SCHWARZER, 2000).

A Carta Magna de 1988 igualou os trabalhadores rurais a todos os trabalhadores brasileiros, possibilitando acesso à Previdência Social através do Princípio do Acesso Universal, o mesmo ocorrendo com idosos e inválidos. Assim, o setor rural informal formado pelo "produtor, parceiro, meeiro e o arrendatário rural, o garimpeiro e o pescador artesanal, bem como respectivos cônjuges que exerçam suas atividades em regime de economia familiar sem empregados permanentes" passou a ter acesso aos benefícios previdenciários: art. 194, $§ 8^{\circ}$, Constituição Federal de 1988 (BRASIL, 2007).

As Leis 8.212/91 e 8.213/91, que regulamentaram o tema, trouxeram modificações significativas no programa previdenciário rural. Segundo Delgado e Cardoso Jr. (1999), as principais mudanças normativas ocorridas foram: i) equiparação de condições de acesso para homens e mulheres (o antigo regime era específico apenas para o responsável pela família); ii) redução do limite de idade para aposentadoria por idade (60 anos para homens e 55 para mulheres); e iii) estabelecimento de um piso de aposentadorias e pensões em um salário mínimo (o regime anterior estabelecia teto em $1 \frac{1}{2}$ salário mínimo para o público do Funrural e pensões limitadas a $30 \%$ do benefício principal).

A comprovação do tempo de atividade rural também mudou, podendo ser documentada na mesma extensão que o período de contribuição 
mínimo previsto para os segurados urbanos (15 anos, desde que atinja a idade mínima). Como documentos para tal, além das possibilidades elencadas para os trabalhadores urbanos, por meio da documentação comprobatória do uso da terra (contrato de parceria ou arrendamento, termo de propriedade do terreno etc.), notas de venda da produção rural (bloco de notas do produtor rural) ou declaração expedida pelo sindicato rural e homologada pelo INSS.

A Lei 8.742, de 1993, conhecida como Lei Orgânica da Assistência Social (Loas), foi, juntamente com as duas leis citadas anteriormente, de grande importância para o segurado rural. Foi substituída a Renda Mensal Vitalícia pelo Beneficio de Prestação Continuada (concedido a partir de 1996): a primeira tinha como um dos requisitos a realização mínima de doze contribuições mensais à Previdência Social e para a segunda não mais havia a necessidade de contribuição prévia, porém a renda familiar mensal per capita do candidato ao benefício deveria ser menor que 1/4 do salário mínimo. O Beneficio de Prestação Continuada não difere entre a clientela rural e a urbana. Para o idoso, a idade de acesso é de 67 anos para homens e mulheres (em 2000 passou a ser de 65 anos). Para a Pessoa Portadora de Deficiência, incluem-se, além da invalidez já contemplada pela Renda Mensal Vitalícia, as deficiências congênitas (SCHWARZER, 2000).

No que tange ao financiamento do sistema previdenciário rural, a Lei 4.214 de 1963 previa uma contribuição de $1 \%$ sobre o valor da primeira comercialização do produto rural, com recolhimento de obrigação legal do próprio produtor agrícola, sendo, de acordo com Malloy (1976), não suficiente a execução do programa, por tornar a fiscalização e o recolhimento das contribuições inviáveis. Para o Prorural/Funrural, o financiamento dos benefícios era feito com uma contribuição de $2 \%$ sobre o valor de comercialização da produção rural a cargo do adquirente. Cobrava-se também uma alíquota de $2,4 \%$ sobre a folha de salários urbana para complementar a estrutura de custeio do Funrural. 
De acordo com Schwarzer (2000), com a Constituição de 1988 e as Leis 8.212 e 8.213 de 1991, a contribuição do segurado especial manteve-se como contribuição sobre a produção comercializada (encargo do comprador), no valor, em 1999, de 2,2\% sobre o preço de venda, sendo $0,1 \%$ destinado ao seguro de acidentes de trabalho e outro $0,1 \%$ ao Serviço Nacional de Aprendizagem Rural (Senar), ao invés de contribuição sobre remuneração percebida, caso do trabalhador urbano.

\section{Metodologia}

Para o desenvolvimento do presente estudo, foram tomadas por base as informações coletadas pelas Pesquisas Nacionais por Amostra de Domicílios (PNAD), no período de 1988 a 2008. Trata-se de um levantamento anual realizado por meio de amostra dos domicílios que abrange todo o país, exceto, anteriormente a 2004, a área rural dos estados da antiga região Norte (Acre, Amapá, Amazonas, Pará, Rondônia e Roraima). A Pesquisa foi interrompida por ocasião dos Censos Demográficos (1970, 1980, 1991 e 2000), além de não ter sido feita em 1994 por razões excepcionais.

A classificação das áreas urbanas e rurais é feita de acordo com a legislação vigente por ocasião dos Censos Demográficos. Para as pesquisas da PNAD de 1988 a 1990, utilizou-se a classificação vigente por ocasião do Censo Demográfico de 1980; para as pesquisas da PNAD de 1992 a 1999, utilizou-se a classificação vigente por ocasião do Censo Demográfico de 1991; e para a pesquisa da PNAD de 2001 a 2008, utilizou-se a classificação vigente por ocasião do Censo Demográfico de 2000.

Ressalta-se, também, que, para as PNADs de 1992 a 1996, foram utilizados os fatores de expansão corrigidos com base na contagem populacional e divulgados juntamente com os microdados da PNAD de 1997. 
Foram utilizados dados individuais das PNADs de 1988 a 1990, 1992, 1993, 1995, 1996 a 1999, 2001 a 2008 fornecidas pelo IBGE, através de CD-ROM anual.

O procedimento metodológico adotado pelo IBGE implica que cada pessoa da amostra representa um determinado número de pessoas da população e os dados individuais são fornecidos com o peso ou fator de expansão de cada indivíduo. Isso permite que os cálculos sejam elaborados ponderando-se cada observação pelo respectivo peso. Todos os cálculos, neste trabalho, foram feitos considerando o peso ou fator de expansão de cada domicílio da amostra da PNAD, analisados apenas os domicílios particulares permanentes com declaração do rendimento domiciliar. Domicílios com rendimentos não declarados foram excluídos da análise.

De acordo com as notas metodológicas do IBGE (2007), "considerou-se como rendimento mensal domiciliar a soma dos rendimentos mensais dos moradores do domicílio, exclusive os das pessoas cuja condição no domicílio fosse pensionista, empregado doméstico ou parente do empregado doméstico". Para obter o rendimento domiciliar per capita, dividiu-se o rendimento mensal domiciliar pelo número de pessoas do domicílio, excluindo pensionistas, empregados domésticos e seus parentes.

Os componentes do rendimento domiciliar são os provenientes do trabalho principal, rendimentos de outros trabalhos, de aposentadorias e pensões, dos aluguéis, doações e outros rendimentos apresentados para as pessoas de dez anos ou mais de idade.

Consideram-se rendimentos de trabalho principal os decorrentes dos pagamentos brutos mensais aos empregados, empregadores e conta própria, sejam advindos do trabalho único (de maior relevância para a formação da renda) que a pessoa de 10 anos ou mais de idade teve no período da pesquisa (semana de referência da PNAD), impondo-se outros critérios para casos especiais ou dos demais trabalhos. 
No conceito de outros trabalhos, caracteriza-se o trabalho remunerado advindo de forma secundária. Os rendimentos de aposentadorias e pensões são aqueles pagos pelo governo federal ou por instituto de previdência federal, estadual ou municipal, entidades seguradoras ou fundos de pensão. Os rendimentos de aluguel incluem sublocação e arrendamento de móveis, imóveis, máquinas, equipamentos, animais etc. O rendimento de doações são os oriundos de doação ou mesada (proveniente de pessoa nãomoradora na unidade domiciliar). Outros rendimentos são os que provêm de juros decorrentes de aplicações financeiras em ativos financeiros de renda fixa e caderneta de poupança, e de programas governamentais de assistência como programa oficial de auxílio educacional (como o bolsaescola) ou social (renda mínima, bolsa família, benefício assistencial de prestação continuada - BPC-LOAS, programa de erradicação do trabalho infantil - PETI e outros) (IBGE, 2007). As análises foram feitas para os residentes nas áreas rurais, cabendo ressaltar que "rural" se refere apenas à localização do domicílio, e não à origem dos rendimentos.

Utilizou-se a decomposição do Índice de Gini para analisar a contribuição das aposentadorias e pensões para a desigualdade da distribuição do rendimento domiciliar per capita na área rural brasileira, de 1988 a 2008. A decomposição considera os componentes que se somam para formar os rendimentos domiciliares: trabalho principal, outros trabalhos, aposentadorias e pensões, aluguéis, doações e outros rendimentos.

Na decomposição do índice de Gini, o trabalho de Pyatt, Chen e Fei (1980) mostra como este índice pode ser decomposto quando se considera a divisão do rendimento analisado em vários componentes.

Seja $z_{i}$ o rendimento da $i$-ésima pessoa. Neste trabalho, considera-se o rendimento domiciliar per capita, considerando que ele é o resultado da soma de $k$ parcelas:

$$
z_{i}=\sum_{h=1}^{k} z_{h i}
$$


Admite-se que os rendimentos $z_{i}$ estão ordenados de maneira que $z_{1} \leq z_{2} \leq \ldots \leq z_{n}$, sendo $n$ o tamanho da população. Então $i$ é a posição de ordem do rendimento .

Pode-se verificar que o índice de Gini $(\mathrm{G})$ da distribuição de $z_{i}$ é

$$
G=\frac{2}{n \mu} \operatorname{cov}\left(z_{i}, i\right)
$$

em que $\mu$ é a média dos .

Pyatt, Chen e Fei (1980) definem a razão de concentração do componente $z_{h i}$ como

$C_{h}=\frac{2}{n \mu_{h}} \operatorname{cov}\left(z_{h i}, i\right)$

em que $\mu_{h}$ é a média dos

A participação do $h$-ésimo componente no rendimento total é

$$
\phi_{h}=\frac{\mu_{h}}{\mu}
$$

Pode-se deduzir que

$$
G=\sum_{h=1}^{k} \phi_{h} C_{h}
$$


Indica-se por $i_{h}$ os números de ordem associados aos valores de $z_{h i}$ se eles fossem colocados em ordem crescente. Os $i_{h}$, da mesma maneira que $i$, variam de 1 a $n$. Note-se, entretanto, que, para determinado $z_{h i}$, o respectivo valor de $i$ ( o número de ordem do correspondente $z_{i}$ ) não vai, em geral, coincidir com $i_{h}$ (a posição desse $z_{h i}$ na ordenação dos valores desse componente). Analogamente a (2), o índice de Gini de $z_{h i}$ é

$$
G_{h}=\frac{2}{n \mu_{h}} \operatorname{cov}\left(z_{h i}, i_{h}\right)
$$

De (3) e (6) obtém-se

$$
R_{h}=\frac{C_{h}}{G_{h}}=\frac{\operatorname{cov}\left(z_{h i}, i\right)}{\operatorname{cov}\left(z_{h i}, i_{h}\right)}
$$

Pyatt, Chen e Fei denominaram $R_{h}$ de "razão de correlação de ordem", ressaltando que não é um coeficiente de correlação de ordem. Eles mostram que

$$
R_{h} \leq 1
$$

De (5) e (7) segue-se que

$$
G=\sum_{h=1}^{k} \phi_{h} R_{h} G_{h}
$$


Essa expressão mostra como o índice de Gini de $z_{i}$ está associado com os índices de Gini de cada componente.

Note-se, na expressão (5), que se todas as razões de concentração $C_{h}$ tivessem o mesmo valor, esse seria, também, o valor de $G$. Dessa forma, pode-se considerar que um componente $z_{h i}$ contribui para aumentar a desigualdade (medida pelo índice de Gini) quando $C_{h}>G$.

\section{Resultados da decomposição do Índice de Gini para o Brasil rural}

O Índice de Gini pode ser considerado uma importante ferramenta na avaliação da distribuição de renda, como exposto neste trabalho, mais especificamente para a área rural. Desse modo, a decomposição do Índice de Gini, conforme parcelas do rendimento domiciliar per capita, observa a participação de cada componente na formação do Gini Global, para cada ano analisado.

A participação do trabalho principal mostrou queda para todo o período, tendo seu pico em 1989 atingindo 88,7\% da participação entre os rendimentos analisados. Em 2008, último ano do estudo, sua taxa de participação nos rendimentos foi de $65,7 \%$, uma variação negativa de 23,0 pontos percentuais. A possível explicação para essa queda pode ser dada pelo aumento da participação dos rendimentos advindos de aposentadorias e pensões que em 1988 era de 5,9\% e em 2008 foi de $25,0 \%$. Tal variação se deve em grande parte aos programas sociais de inclusão dos trabalhadores rurais na década de 1990.

A Tabela 1 mostra a participação percentual $\left[(\%) \phi_{k}\right]$ dos componentes do rendimento domiciliar per capita para o Brasil Rural, no período 1988 a 2008 . 
A regulamentação estabelecida pelas Leis 8.212 e 8.213 em 1991 significou uma alteração conceitual profunda para o programa previdenciário rural no Brasil. Os trabalhadores rurais e os segurados em regime de produção familiar foram incluídos no plano de benefícios normal do Regime Geral de Previdência Social, extinguindo-se o tratamento administrativo institucional que era dado para esses casos.

Schwarzer (2000) elencou três especificidades atribuídas às Leis 8.212 e 8.213 de 1991: a primeira continuou residindo na forma de contribuição do segurado especial, em que, em vez de contribuições sobre a remuneração percebida, manteve-se a contribuição sobre a produção comercializada, cujo recolhimento é encargo do comprador [em 1999 de $2,2 \%$ sobre o valor de venda, sendo $0,1 \%$ destinado ao seguro de acidentes de trabalho e outro $0,1 \%$ ao Serviço Nacional de Aprendizagem Rural (Senar)]. Dessa maneira, os trabalhadores segurados passaram a ter o mesmo piso salarial a que os segurados normais tinham por direito. $\mathrm{O}$ piso de benefícios para aposentadorias e pensões passou a ser de um salário mínimo (aplicável também aos benefícios concedidos antes de 1988) e as mulheres vieram a ter acesso à aposentadoria independentemente de o cônjuge já ser beneficiário ou não. 
REVISTA DE ECONOMIA E AGRONEGÓCIO, VOL.9, $N^{\circ} 1$

Tabela 1 - Participação percentual dos componentes do rendimento domiciliar per capita. Brasil Rural, de 1988 a 2008.

\begin{tabular}{|c|c|c|c|c|c|c|c|c|c|}
\hline \multirow{2}{*}{ Parcelas } & \multicolumn{9}{|c|}{ Brasil Rural - Participação percentual dos rendimentos $\left[(\%) \phi_{k}\right]$} \\
\hline & 1988 & 1989 & 1990 & 1992 & 1993 & 1995 & 1996 & 1997 & 1998 \\
\hline 1 & 88,4 & 88,7 & 87,2 & 78,5 & 78,0 & 76,8 & 79,2 & 77,6 & 75,0 \\
\hline 2 & 2,5 & 2,8 & 3,4 & 3,4 & 4,4 & 4,7 & 3,8 & 4,1 & 4,2 \\
\hline 3 & 5,9 & 6,0 & 6,7 & 15,5 & 14,2 & 15,8 & 14,6 & 15,7 & 17,8 \\
\hline 4 & 1,4 & 0,7 & 1,2 & 0,5 & 0,9 & 1,4 & 1,2 & 1,3 & 1,3 \\
\hline 5 & - & - & - & 0,4 & 0,4 & 0,7 & 0,6 & 0,7 & 0,7 \\
\hline 6 & 1,8 & 1,8 & 1,4 & 1,7 & 2,2 & 0,7 & 0,7 & 0,6 & 1,0 \\
\hline Total & 100,0 & 100,0 & 100,0 & 100,0 & 100,0 & 100,0 & 100,0 & 100,0 & 100,0 \\
\hline \multirow{2}{*}{ Parcelas } & \multicolumn{9}{|c|}{ Brasil Rural - Participação percentual dos rendimentos $\left[(\%) \phi_{k}\right]$} \\
\hline & 1999 & 2001 & 2002 & 2003 & 2004 & 2005 & 2006 & 2007 & 2008 \\
\hline 1 & 75,8 & 71,2 & 70,4 & 70,8 & 69,3 & 68,0 & 66,3 & 66,1 & 65,7 \\
\hline 2 & 4,0 & 3,7 & 3,5 & 3,0 & 3,3 & 3,8 & 3,6 & 3,0 & 3,2 \\
\hline 3 & 17,2 & 21,1 & 21,9 & 22,4 & 22,1 & 22,6 & 23,5 & 24,1 & 25,0 \\
\hline 4 & 1,3 & 1,5 & 1,2 & 1,1 & 1,0 & 0,9 & 1,0 & 1,1 & 0,9 \\
\hline 5 & 0,7 & 0,5 & 0,6 & 0,5 & 0,4 & 0,4 & 0,4 & 0,3 & 0,3 \\
\hline 6 & 0,9 & 1,9 & 2,4 & 2,2 & 3,9 & 4,4 & 5,1 & 5,5 & 4,9 \\
\hline Total & 100,0 & 100,0 & 100,0 & 100,0 & 100,0 & 100,0 & 100,0 & 100,0 & 100,0 \\
\hline
\end{tabular}

Fonte: Elaboração própria a partir de IBGE - dados individuais das PNADs de 1988 a 2008.

1 - Trabalho principal; 2 - Outros trabalhos; 3 -Aposentadorias e pensões; 4 -Aluguel; 5 -Doações; 6 - Outros rendimentos. 
Flávio Braga de Almeida-Gabriel, Carlos Roberto Ferreira

\& Solange de Cássia Inforzato de Souza

A segunda especificidade trata da idade de acesso à aposentadoria por idade que passou a ser mais baixa para o setor rural frente aos segurados normais: fixada em 55 anos para mulheres e 60 anos para homens no meio rural e 65 anos para homens e 60 anos para mulheres entre segurados normais.

A terceira especificidade corresponde às formas de comprovação do tempo de atividade rural, podendo ser feita, além da forma à qual se sujeitam os trabalhadores urbanos, por meio da documentação comprobatória do uso da terra, notas de venda da produção rural ou declaração expedida pelo sindicato rural e homologada pelo INSS, devendo ser documentada na mesma extensão do período de contribuição mínimo previsto para os segurados urbanos.

Com a aprovação da Lei 8.742 (Lei Orgânica da Assistência Social LOAS) na qual a renda mensal vitalícia foi substituída pelo beneficio de prestação continuada, sua diferença em relação ao primeiro é que o primeiro previa para os idosos, advindos do meio rural, a partir dos 70 anos de idade ou pessoa inválida (que não completassem os requisitos estabelecidos para a aposentadoria/pensão), um valor de meio salário mínimo, bem como o seguro de acidentes de trabalho rural. Já o segundo, extinguia o primeiro em favor da universalização dos benefícios entre os beneficiários advindos do meio rural e urbano, passando o valor mínino do auxílio monetário a ser de um salário mínimo mensal, com idade de acesso de 65 anos (a partir de 2000) tanto para homem quanto para mulher. Além disso, o benefício de prestação continuada não prevê mais o requisito da contribuição prévia, porém a renda familiar mensal per capita do candidato ao benefício precisa ser menor que 1/4 do salário mínimo.

A Tabela 2 mostra a razão de concentração (C) dos componentes do rendimento domiciliar per capita $C\left(x_{k} \mid y\right)$ para o Brasil Rural. Sabe-se que um componente da renda contribui para aumentar a desigualdade quando a razão de concentração for maior que o Índice de Gini. 
Para o Brasil Rural, conforme Tabela 2, o período entre 1988 e 2008 apresentou significativa redução na concentração de renda. Em 1988, em que o Índice de Gini foi de 0,559, passando a 0,498 em 2008, houve uma redução na concentração de renda da área rural de 10,91\%.

Tabela 2 - Razão de concentração (C) na decomposição do Índice de Gini do rendimento domiciliar per capita. Brasil Rural, de 1988 a 2008.

\begin{tabular}{|c|c|c|c|c|c|c|c|c|c|}
\hline \multirow{2}{*}{ Parcelas } & \multicolumn{9}{|c|}{ Brasil Rural - Razão de concentração $C\left(x_{k} \mid y\right)$} \\
\hline & 1988 & 1989 & 1990 & 1992 & 1993 & 1995 & 1996 & 1997 & 1998 \\
\hline 1 & 0,561 & 0,574 & 0,539 & 0,530 & 0,574 & 0,531 & 0,556 & 0,551 & 0,547 \\
\hline 2 & 0,644 & 0,712 & 0,700 & 0,608 & 0,607 & 0,606 & 0,646 & 0,603 & 0,454 \\
\hline 3 & 0,417 & 0,408 & 0,415 & 0,570 & 0,549 & 0,549 & 0,504 & 0,534 & 0,565 \\
\hline 4 & 0,882 & 0,804 & 0,852 & 0,801 & 0,874 & 0,889 & 0,858 & 0,864 & 0,868 \\
\hline 5 & - & - & - & 0,093 & 0,237 & 0,304 & 0,301 & 0,271 & 0,232 \\
\hline 6 & 0,593 & 0,648 & 0,586 & 0,816 & 0,844 & 0,718 & 0,821 & 0,746 & 0,581 \\
\hline Total & 0,559 & 0,571 & 0,541 & 0,543 & 0,579 & 0,542 & 0,556 & 0,553 & 0,549 \\
\hline \multirow{2}{*}{ Parcelas } & \multicolumn{9}{|c|}{ Brasil Rural - Razão de concentração $C\left(x_{k} \mid y\right)$} \\
\hline & 1999 & 2001 & 2002 & 2003 & 2004 & 2005 & 2006 & 2007 & 2008 \\
\hline 1 & 0,543 & 0,528 & 0,505 & 0,530 & 0,517 & 0,506 & 0,508 & 0,519 & 0,502 \\
\hline 2 & 0,542 & 0,623 & 0,515 & 0,518 & 0,580 & 0,552 & 0,627 & 0,610 & 0,592 \\
\hline 3 & 0,548 & 0,577 & 0,562 & 0,572 & 0,574 & 0,573 & 0,573 & 0,550 & 0,569 \\
\hline 4 & 0,843 & 0,890 & 0,883 & 0,885 & 0,837 & 0,813 & 0,833 & 0,844 & 0,840 \\
\hline 5 & 0,179 & 0,162 & 0,305 & 0,154 & 0,218 & 0,078 & 0,072 & 0,043 & 0,169 \\
\hline 6 & 0,500 & 0,101 & 0,112 & 0,040 & 0,021 & 0,092 & 0,021 & 0,139 & $-0,016$ \\
\hline Total & 0,545 & 0,537 & 0,512 & 0,531 & 0,514 & 0,506 & 0,504 & 0,511 & 0,498 \\
\hline
\end{tabular}

Fonte: Elaboração própria a partir de IBGE - dados individuais das PNADs de 1988 a 2008.

1 - Trabalho principal; 2 - Outros trabalhos; 3 -Aposentadorias e pensões; 4 -Aluguel; 5 - Doações; 6 - Outros rendimentos. 
A leitura desses dados levanta dois fatores importantes já enfatizados em Soares (2006). O primeiro diz respeito à política social aplicada pelo Estado, particularmente aos programas de transferência de renda às camadas de menor poder aquisitivo da população brasileira. Segundo o autor, a aposentadoria rural pode ser considerada a mais antiga entre essas políticas, intensificada na década de 1990 pelas Leis 8.212 e 8.213 de 1991 e a Lei 8.742 de 1993. Em suas palavras, "O piso do Regime Geral da Previdência Social, também indexado ao salário mínimo, pode ser pensado como um programa de transferência de renda aos mais pobres, apesar de não ser regido por nenhuma regra nesse sentido". Entretanto, diferentemente ao que foi considerado por Soares (2006), o Índice de Gini, para as aposentadorias e pensões, mostrou elevação na concentração de renda, passando de 0,417 em 1988 para 0,569 em 2008, uma variação positiva de $36,5 \%$, demonstrando não ser ela a responsável pela queda da desigualdade.

O segundo fator faz referência ao mercado de trabalho. O autor atribui grande relevância ao salário mínimo real, que sofreu alteração significativa entre 1994 e 2004, passando de $\mathrm{R} \$ 170,00$ em setembro de 1994 para $\mathrm{R} \$ 275,00$ em setembro de 2004, podendo ele ser responsável pela redistribuição de renda diretamente via mercado de trabalho. Em conformidade com o autor, os rendimentos com o trabalho principal tiveram considerável redução na concentração de renda entre os anos analisados, passando de 0,561 em 1988 0,502 em 2008, uma redução de 10,5\% para esse componente.

A despeito dessa redução do índice de Gini a partir da segunda metade dos anos 90, o comportamento do rendimento das aposentadorias e pensões tem apresentado uma força contrária, já que desde 1998 tem colaborado para a concentração da renda na área rural. Isso se verifica tecnicamente observando os valores da razão de concentração das aposentadorias e pensões acima dos valores do índice de Gini total, conforme a Tabela 2. De 1998 a 2008, a referida razão de concentração foi sistematicamente maior, contribuindo, assim, para a concentração da renda, compensada pelas outras fontes de renda. 
A Tabela 3 mostra a participação de cada componente para a formação do Índice de Gini e a sua participação, em termos percentuais, para a formação do Índice de Gini Global no Brasil Rural. Observa-se que o rendimento do trabalho principal é, em todo o período, o componente com a maior participação na formação do Índice de Gini do rendimento domiciliar per capita, seguido pelo rendimento de aposentadorias e pensões.

Tabela 3 - Parcelas do índice de Gini $\left[\phi_{k} C\left(x_{k} \mid y\right)\right]$ na formação do índice de Gini Global dos componentes do rendimento domiciliar per capita. Brasil Rural, de 1988 a 2008.

\begin{tabular}{|c|c|c|c|c|c|c|c|c|c|}
\hline \multirow{2}{*}{ Parcelas } & \multicolumn{9}{|c|}{ Brasil Rural - Parcelas do Índice de Gini $\left.\Phi_{k} C\left(x_{k} \mid y\right)\right]$} \\
\hline & 1988 & 1989 & 1990 & 1992 & 1993 & 1995 & 1996 & 1997 & 1998 \\
\hline 1 & 0,496 & 0,509 & 0,470 & 0,416 & 0,447 & 0,407 & 0,440 & 0,427 & 0,410 \\
\hline 2 & 0,016 & 0,020 & 0,024 & 0,020 & 0,027 & 0,028 & 0,024 & 0,025 & 0,019 \\
\hline 3 & 0,024 & 0,025 & 0,028 & 0,088 & 0,078 & 0,087 & 0,074 & 0,084 & 0,101 \\
\hline 4 & 0,012 & 0,005 & 0,010 & 0,004 & 0,008 & 0,013 & 0,010 & 0,012 & 0,012 \\
\hline 5 & - & - & - & 0,0003 & 0,001 & 0,002 & 0,002 & 0,002 & 0,002 \\
\hline 6 & 0,011 & 0,012 & 0,008 & 0,014 & 0,019 & 0,005 & 0,006 & 0,005 & 0,006 \\
\hline Total & 0,559 & 0,571 & 0,541 & 0,543 & 0,579 & 0,542 & 0,556 & 0,553 & 0,549 \\
\hline \multirow{2}{*}{ Parcelas } & \multicolumn{9}{|c|}{ Brasil Rural - Parcelas do Índice de Gini $\left[\phi_{k} C\left(x_{k} \mid y\right)\right]$} \\
\hline & 1999 & 2001 & 2002 & 2003 & 2004 & 2005 & 2006 & 2007 & 2008 \\
\hline 1 & 0,411 & 0,376 & 0,356 & 0,376 & 0,358 & 0,344 & 0,337 & 0,343 & 0,330 \\
\hline 2 & 0,022 & 0,023 & 0,018 & 0,016 & 0,019 & 0,021 & 0,023 & 0,018 & 0,019 \\
\hline 3 & 0,094 & 0,122 & 0,123 & 0,128 & 0,127 & 0,129 & 0,135 & 0,133 & 0,142 \\
\hline 4 & 0,011 & 0,014 & 0,010 & 0,010 & 0,009 & 0,007 & 0,008 & 0,009 & 0,007 \\
\hline 5 & 0,001 & 0,001 & 0,002 & 0,001 & 0,0008 & 0,0003 & 0,0003 & 0,0001 & 0,0006 \\
\hline 6 & 0,005 & 0,002 & 0,003 & 0,001 & 0,0008 & 0,004 & 0,001 & 0,008 & 0,000 \\
\hline Total & 0,545 & 0,537 & 0,512 & 0,531 & 0,514 & 0,506 & 0,504 & 0,511 & 0,498 \\
\hline
\end{tabular}

Fonte: Elaboração própria a partir de IBGE - dados individuais das PNADs de 1988 a 2008.

1 - Trabalho principal; 2 - Outros trabalhos; 3 -Aposentadorias e pensões; 4 - Aluguel; 5 - Doações; 6 - Outros rendimentos. 
No Brasil Rural, a parcela de aposentadorias e pensões participou com a segunda maior parcela do Índice de Gini Total. A partir de 1995 e ao longo dos anos 90, essa participação foi crescente, chegando em 1998 a 18,4\%. Os anos de 2001 a 2008 apresentam as maiores participações desse componente no Índice de Gini Total. Entre 1996 e 2008, no Brasil Rural, a parcela do rendimento do trabalho principal diminuiu 0,110 , enquanto a parcela do rendimento de aposentadorias e pensões cresceu 0,068 .

\section{Considerações Finais}

O objetivo do artigo foi analisar a evolução e medir a concentração de renda na área rural brasileira após a promulgação da Legislação de 1988 e as leis que se seguiram no âmbito da seguridade do trabalhador rural (Lei 8.212/91 e Lei 8213/91). A análise dos resultados permitiu verificar que houve desconcentração de renda no período avaliado, especificamente após 1989.

Percebe-se que a participação do trabalho principal mostrou queda para todo o período, passando de $88,4 \%$ da participação entre os rendimentos em 1989 para 65,7\% em 2008, sendo compensada pela elevação da participação dos rendimentos advindos de aposentadorias e pensões, que passou de 5,9\% em 1989 para 25,0 em 2008, fato este gerado pelo aumento de participantes em programas sociais de inclusão dos trabalhadores rurais, iniciado na década de 1990.

O cálculo da concentração de renda pelo Índice de Gini no período entre 1988 e 2008 evidencia significativa redução na concentração de renda. Enquanto para 1989 o índice foi de 0,571, em 2008 esse valor caiu para 0,498, mostrando uma redução na concentração de renda do setor rural da ordem de 0,073. Este fato pode ser explicado, em parte, pelo mercado de trabalho, em que o salário mínimo real sofreu alteração significativa entre 1994 e 2004, podendo ele ser responsável pela redistribuição de renda diretamente via mercado de trabalho. Porém, não se pode 
considerar que tenha havido redução da concentração de renda oriunda dos programas sociais que abrangem a previdência social, observado pela razão de concentração das aposentadorias e pensões maior que o índice de Gini total: em 1988 seu valor era de 0,417, passando para 0,569 em 2008, elevando-se, portanto, 0,152.

Quando avaliada a participação de cada componente do rendimento domiciliar per capita na formação do Índice de Gini para o Brasil Rural, percebe-se qual efetividade teve o componente trabalho principal para a redução do índice global. Entre 1988 e 2008, a parcela do rendimento do trabalho principal diminuiu 0,166 , em contraponto, a parcela do rendimento de aposentadorias e pensões cresceu 0,118. Entretanto, dada a magnitude da participação do trabalho principal na renda em 2008 de 66,7\%, em última análise prevaleceu o trabalho principal, contribuindo significativamente para a redução da concentração de renda no setor rural brasileiro.

\section{Referências}

BRASIL. Constituição de 1988. Constituição da República Federativa do Brasil. Organização de Pinto, Antonio Luiz de Toledo; Windt, Márcia Cristina Vaz dos Santos; Céspedes, Livia. 40ª edição. São Paulo: Saraiva, 2007.

CAMPANHOLA, C.; GRAZIANO DA SILVA, J. (Eds.). O novo rural brasileiro: uma análise regional. Jaguariúna: Embrapa-Meio Ambiente/ Instituto de Economia, Universidade Estadual de Campinas, 2000.

CAMPOLINA, B.; SILVEIRA, F. G.; MAGALHÃES, L. C. G. O mercado de trabalho Rural: evolução recente, composição da renda e dimensão regional. (Texto para Discussão n ${ }^{0} 1398$ - IPEA). Rio de Janeiro, mar. 2009. 
DEDECCA, C. S.; BALLINI, R.; MAIA, A. G. Rendimentos previdenciários e distribuição de renda. In: FAGNANI, E.; POCHMANN, M. (Org.). Debates contemporâneos: economia social e do trabalho, n. 1: Mercado de trabalho, relações sindicais, pobreza e ajuste fiscal. São Paulo, LTr, p. 172-179. 2007.

DEDECCA, C. S.; ROSANDISKI, E. N.; BARBIERI, C. V.; JUNGBLUTH, A. Salário mínimo, benefício previdenciário e as famílias de baixa renda, Síntese Metodológica. Revista Brasileira de Estudos Populacionais, São Paulo, v. 23, n. 2, p. 317-329, jul./dez. 2006.

DELGADO, G. C.; CARDOSO JR, J. C. C. O Idoso e a Previdência Rural no Brasil: a experiência recente da universalização. (Texto para Discussão n ${ }^{0} 688$ - IPEA). Rio de Janeiro, dez. 1999.

DEL GROSSI, M.; GRAZIANO DA SILVA, J. Mudanças recentes no mercado de trabalho rural. Parcerias Estratégias, n. 22, Brasília: CGEE, jun. 2006.

FERREIRA, C. R. Aposentadorias e distribuição da renda no Brasil: uma nota sobre o período 1981 a 2001. Revista Brasileira de Economia, v. 60 , n. 3, p. 247-260, jul./set. 2006.

. Participação das aposentadorias e pensões na desigualdade da distribuição da renda no Brasil no período de 1981 a 2001. Piracicaba, 2003. 136p. Tese (Doutorado) - Escola Superior de Agricultura "Luiz de Queiroz", Universidade de São Paulo.

FERREIRA, C. R.; ALMEIDA-GABRIEL, F. B.; SOUZA, S. C. I.; BAPTISTELLA, J. C. F. Concentração de renda per capita no Brasil e Brasil Rural, 1981 a 2006: uma avaliação das aposentadorias e pensões. In: CONGRESSO BRASILEIRO DE ECONOMIA E SOCIOLOGIA RURAL, 47. 2009, Porto Alegre, Anais... Porto Alegre: SOBER.

FERREIRA, C. A.; SOUZA, S. As aposentadorias e pensões e a concentração dos rendimentos domiciliares per capita no Brasil e na sua 
área rural: 1991 a 2003. Revista de Economia e Sociologia Rural, v. 45, n. 4, p. 985-1011, 2007.

FERREIRA, F. H. G.; LEITE, P. G.; LITCHFIELD, J. A. The rise and fall of Brazilian inequality, 1981-2004 The World Bank. Washington, 2006 (Policy Research Working Paper Series, n. 3.867).

GRAZIANO DA SILVA, J. A nova dinâmica da agricultura brasileira. Campinas: Universidade Estadual de Campinas, Edições Campinas, 1996.

GRAZIANO DA SILVA, J.; DEL GROSSI, M. E. Rural nonfarm employment and incomes in Brazil: patterns and evolution. World Development, v. 29, n. 3, p. 443-453, 2001.

HOFFMANN, R. Desigualdade da distribuição de renda no Brasil: a contribuição de aposentadorias e pensões e de outras parcelas do rendimento domiciliar per capita. Economia e Sociedade, Campinas, v. 18, n. 1 (35), p. 213-231, abr. 2009.

. Inequality in Brazil: the contribution of pensions. Revista

Brasileira de Economia, v. 57, n. 4, p. 755-773, out./dez. 2003.

HOFFMANN, R; LEONE, E. T. Participação da mulher no mercado de trabalho e desigualdade da renda domiciliar per capita no Brasil: 19812002. Nova Economia, Belo Horizonte, v. 14, n. 2, p. 35-58, maio/ago. 2004.

IBGE - INSTITUTO BRASILEIRO DE GEOGRAFIA E ESTATÍSTICA. Pesquisa Nacional por Amostra de Domicílios (compact disc). Rio de Janeiro, 1988-89, 1990, 1992-93, 1995-99, 2001-08.

IPEA - INSTITUTO DE PESQUISA ECONÔMICA APLICADA. Sobre a Recente Queda da Desigualdade de Renda no Brasil. Nota Técnica. Brasília: IPEA, ago. 2008. 
Flávio Braga de Almeida-Gabriel, Carlos Roberto Ferreira \& Solange de Cássia Inforzato de Souza

JAMES, E; BROOKS, S. A economia política da reforma estrutural do sistema previdenciário. In: A Economia Política da Reforma da Previdência. Brasília: PARSEP/MPAS/SPS, p.49-91. (Coleção Previdência Social. Traduções, 9). 2001.

KAGEYAMA, A. Mudanças no trabalho rural no Brasil, 1992-2002. Agricultura em São Paulo. São Paulo, v. 51, n. 2, p. 71-84, 2004.

. Diversificação das rendas nos domicílios agrícolas no Brasil, 1992 a 2001. Economia e Sociedade, Campinas, v. 12, n. 1, jan./ jun. 2003.

MALLOY, J. M. Authoritarianism and the extension of social security protection to the rural sector in Brazil. Pittsburgh, 1976, mimeo.

NICHOLSON, B. A previdência injusta: como o fim dos privilégios pode mudar o Brasil. São Paulo: Geração Editorial, 2007. 334 p.

PYATT, G.; CHEN, C.; FEI, J. The distribution of income by factor components. The Quartely Journal of Economics, v.95, n.3, p.451473, nov. 1980.

SCHWARZER, H. Impactos Socieconomicos do Sistema de Aposentadorias Rurais no Brasil - evidências empíricas de um estudo de caso no Estado do Pará. (Texto para Discussão n ${ }^{0} 729$ IPEA). Rio de Janeiro, jun. 2000.

SOARES. S.S.D. Distribuição de renda no Brasil de 1976 a 2004 com ênfase no período entre 2001 e 2004. Rio de Janeiro, IPEA, 2006.

STEPHANES, R. Reforma da previdência sem segredos. Rio de Janeiro: Record, 1998.

THOMPSON, L. Mais Velha e Mais Sábia: A Economia dos Sistemas Previdenciários. Brasília: MPAS, 2000. P.09 (Coleção Previdência Social. v.04). 
REVISTA DE ECONOMIA E AGRONEGÓCIO, VOL.9, $N^{\circ} 1$ 